\title{
Ismael Kong Urbina (1942 - 2008)
}

Los ictiólogos chilenos hemos querido hacer un homenaje a nuestro amigo y colega, el Profesor Ismael Kong Urbina a través de un volumen especial en la Revista de Biología Marina y Oceanografía, comunicando algunos de nuestros resultados científicos acerca de la biología de peces, nuestro punto de encuentro en las ciencias.

Estos ictiólogos son los siguientes: Germán Pequeño, Julio Lamilla, Ricardo Galleguillos, Ciro Oyarzún, Eduardo Tarifeño, Mauricio Landaeta, Javier Chong, Fernando Balbontín, Brian Dyer, Enzo Acuña, Héctor Flores, Marcelo Oliva,

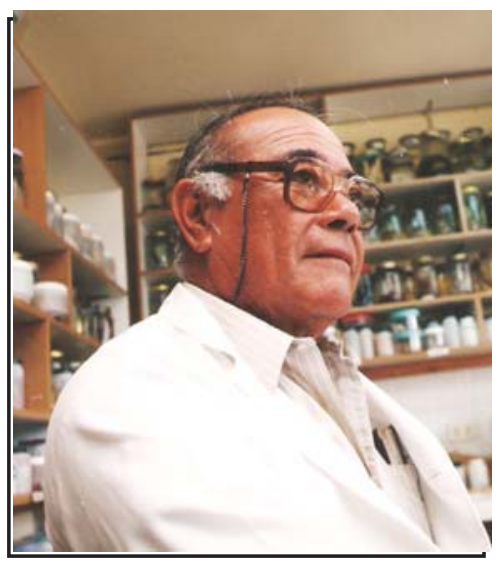
Walter Sielfeld, , Gabriel Claramunt, Ricardo Bravo, Víctor H. Ruíz, Leonardo Castro, Roberto Meléndez, Irma Vila, Laura Huaquín, Evelyn Habit, María Teresa González, Gloria Arratia y Cecilia Cancino.

Ismael fue Académico de la Universidad de Antofagasta, donde se desempeñó como docente en las carreras de Ingeniería en Acuicultura, Ecología Marina, Ingeniería en Alimentos y Pedagogía en Biología y Ciencias, para las cuales dictaba las cátedras de Zoología, Ictiología y Ecología, siendo esta última la más recordada por todos sus alumnos...... incluso uno de ellos escribe que desde 1996 a la fecha de su muerte, no olvida la definición de ......«ecología es el estudio científico de las interrelaciones que determinan la distribución y abundancia de los organismos en un área y tiempo»...... Esto es lo que en pedagogía llamamos un aprendizaje significativo, producto del diseño de estrategias de enseñanza que incluyen la movilización de los contenidos conceptuales y procedimentales en contextos valóricos.

Sin excepción alguna, sus alumnos lo definen como un "Maestro", la más alta jerarquía a la cual puede ser elevado un docente universitario, difícil de alcanzar y que es privativa de aquellos que dedican su vida a la docencia; es que Don Ismael, como muchos lo llamamos en algún momento, dedicó su vida a la enseñanza de las ciencias a través de la ictiología.

Paola Iratchet, quien fue su ayudante, colaboradora y coinvestigadora escribe:

"Quiero expresar mi pesar no solo en mi nombre, sino en el de todos aquellos que fuimos sus alumnos y que me han hecho llegar su profundo pesar y tristeza por la pérdida de nuestro maestro. Entonces he pensado por primera vez, que este sentimiento que tenía por Don Ismael no era solo en singular sino también en plural y son muchos los que nos sentimos marcados por su presencia en nuestras vidas. 
Conocí al profesor Kong a los 12 ó 13 años, cuando asistí a un encuentro de las Juventudes Científicas, y en esa oportunidad él nos dio una charla. Quedé tan impactada con aquel hombre tan alto y de fuerte voz, que pensé que algún día yo quería ser como aquel «señor». La verdad es que no entendí mucho de lo que él hablaba, pero estaba segura que si lo hacía con tanta pasión y entusiasmo, debía ser algo maravilloso.

Así fue como entré a estudiar Acuicultura y me encontré con Don Ismael en aquel espacio mágico. Los primeros años paseaba con cautela por fuera de su oficina, que era una antigua cabaña de madera, que le daba un carácter más misterioso aún. Sin atreverme a preguntar, me conformaba con pensar que algún día tendría la oportunidad de ganarme un espacio, pero estaba segura que debía esforzarme mucho. Así con el tiempo, pasó la imagen de admiración a un profundo respeto.

Cuando tuve la primera clase con él, ya tenía la certeza que de alguna u otra manera yo debía ganarme el privilegio de estar en el laboratorio de Ictiología. Así comencé a esforzarme mucho más en sus clases, hacia doble turno en el laboratorio, iba los días sábados, pero todo aquello no era suficiente, porque el profesor ni siquiera recordaba mi nombre, o al menos eso creía yo... Pero fui constante, muy constante por primera vez en mi vida y no claudiqué en el empeño de llegar a ser algún día su ayudante. Creo que el conjunto de todas aquellas pequeñas luchas hicieron que con los años, me permitiera trabajar con él, en el que para mí ya no era un laboratorio, sino un Templo de Sabiduría... Y ahí aprendí la lección que hasta el día de hoy la recuerdo, casi como la enseñanza de un padre, «nunca es suficiente el esfuerzo y la lucha en nuestro vivir, cuando se trata de cumplir un objetivo». Sin darme cuenta yo me había empeñado en ser su ayudante y me había esforzado más que nunca en la vida.

Fueron años muy buenos, organizamos juntos la IV Reunión Bianual de Ictiología aquí en Antofagasta y creo no equivocarme al afirmar que fue una gran alegría para él, porque pudo reunir en esta ciudad a una familia de profesionales que sin lugar a dudas fueron sus amigos en este mágico sueño de la ciencia, la Ictiología. Hubo dos seminarios, de conservación de áreas protegidas y de aves y mamíferos, que también nos hicieron trabajar duro. Lo mejor de todo, que al final de cada una de estas etapas él se sentía tan feliz y yo así lo sabía porque me tocaba la cabeza. Yo creo que llegó a trabajar en el Fenómeno del Niño, por los peces."

Por otra parte, mi cercanía con Ismael fue a través de la morfología......... sabía de un profesor Ictiólogo que estudiaba y describía la «osteología de peces» y cuando lo observé entre los participantes de los encuentros de las Ciencias del Mar, me pareció un hombre más bien silencioso, de rostro sereno y firmes convicciones que hacía presente cada vez que intervenía en las discusiones académicas.

He estudiado la osteología de varias especies de peces chilenos, todos de baja talla y me preguntaba cómo hacía Ismael para confeccionar los esquemas de las estructuras y las relaciones espaciales con tanta precisión a ojo desnudo y casi no lo pude creer cuando lo vi trabajar; es que la técnica que utilizaba requiere de una gran dedicación y 
absoluta precisión en las observaciones, pues él trabajaba a escala con papel milimetrado, un verdadero arte; por ello que no es de extrañar su condición de maestro, pues Ismael como pocos he conocido, formaba a sus discípulos utilizando la enseñanza del oficio.

Su generosidad sin límites posibilitó que yo pudiera realizar mi tesis, le escribí para preguntarle si entre sus recolectas contaba con especímenes de Scartichthys gigas, me respondió que no tenía, pero que él mismo los recolectaría y así fue; pero además tomó todas las precauciones para enviarme dos hermosos especímenes vivos pues sabía que yo necesitaba observarlos mientras se alimentaban. Posteriormente formó parte de mi comisión de tesis, fue estricto y riguroso en sus comentarios y cuando todo terminó después del examen, se dibujó una sonrisa en su rostro y me dijo: «te felicito has hecho un gran trabajo científico, espero que continúes en la docencia».

Tuve la posibilidad de compartir junto a Ismael en la última reunión científica en la cual pudo participar, la VII Reunión de Ictiología realizada en Valdivia en enero del 2004. Acompañado por algunos de sus alumnos nos deleitó con descripciones osteológicas de varias especies marinas, que incluyó descripciones de desarrollo embrionario y donde centramos nuestras discusiones en la importancia de la enseñanza de la Ictiología, como muy bien expresa Germán Pequeño en el prólogo de la Gayana 69(1) 148: 2005. Abordamos también el tema de la importancia de la comunicación científica en la formación de los nuevos profesionales chilenos. Recuerdo que Ismael fue absolutamente crítico en relación a la pérdida del interés de los científicos por la docencia, frente a la inminente presión de las autoridades universitarias por la productividad científica medida por el número de publicaciones; destacó la importancia de los prácticos o laboratorios, las salidas a terreno cada vez menos frecuentes y por supuesto, nuestra innegable responsabilidad en la formación de profesores de ciencias.

Mi última comunicación con Ismael se produjo en diciembre del año 2007, le envié una tarjeta de navidad aunque sabía que ya no respondía los correos y cuál fue mi más grata sorpresa.... respondió a mi mensaje con un afectuoso saludo de navidad.

Gracias Profesor Kong por haber sido el «maestro» de tus discípulos y por ser inspiración para aquellos que nos dedicamos con pasión a la formación de personas a través de la enseñanza de la biología de peces chilenos.

Prof. Cecilia Cancino Araya 